Linguagem em (Dis)curso - LemD, v. 8, n. 3, p. 487-517, set./dez. 2008

\title{
OS ESTUDOS DE LETRAMENTO E A FORMAÇÃO DO PROFESSOR DE LÍNGUA MATERNA*
}

Angela B. Kleiman**

\begin{abstract}
Resumo: Este trabalho tem por objetivo discutir algumas contribuições dos Estudos do Letramento - o estudo das práticas relacionadas com a escrita em toda atividade da vida social — para a reflexão sobre a formação do professor de língua materna. Primeiramente, discutiremos aspectos éticos dessa abordagem, relacionados ao método qualitativo da pesquisa, que resguardam o pesquisador do perigo, sempre constante, de seus resultados de pesquisa serem utilizados para a reprodução de críticas e estereótipos sobre o docente. Em seguida, analisaremos, em documentos que prescrevem, avaliam ou informam as ações do professor, as exigências em relação aos saberes específicos dos alfabetizadores e professores de língua materna. Finalmente, com base na análise crítica dessas exigências, exploraremos uma alternativa de formação baseada na participação na prática social.

Palavras-chave: letramento; formação do professor; língua materna; prática social.
\end{abstract}

\section{INTRODUÇÃO}

Nos últimos quinze anos, temos presenciado uma situação de efervescência no Brasil no que diz respeito à produção de documentos governamentais - leis, normas e preceitos - destinados a regular e melhorar o ensino fundamental e médio no país. Do ponto de vista das

\footnotetext{
* Agradecemos ao CNPq pelo auxílio, via edital Universal/2007, ao Projeto 'Letramento do professor: práticas acadêmicas e construção de saberes'. Este trabalho integra as pesquisas desenvolvidas pelo Grupo Letramento do Professor, certificado pela Unicamp no Diretório CNPq. Ver site <http://www.letramento.iel.unicamp.br> .

** Professora titular do Departamento de Lingüística Aplicada do Instituto de Estudos da Linguagem da Unicamp. Pesquisadora CNPq. Doutora em Lingǘstica. E-mail: <akleiman@mpc.com.br>.
} 


\section{8}

práticas de letramento envolvidas, assistimos a uma verdadeira onda de novos eventos de letramento - as avaliações de alunos na escola, de egressos da universidade, de livros didáticos, por exemplo - e à produção de textos dos mais diversos gêneros - testes, guias, parâmetros - para agir nesses eventos.

As mudanças no sistema educacional em curso, decorrentes de todo esse trabalho, criam uma situação de incerteza que desestabiliza o professor alfabetizador e o professor de língua materna, como já apontei em trabalho anterior (KLEIMAN, 2006). De fato, a publicação dos Parâmetros Curriculares Nacionais (PCN) para o Ensino Fundamental (1997) e para o Ensino Médio (1999, 2001, 2006), o estabelecimento de um sistema de avaliação permanente do livro didático (PNLD, 1997); as diversas avaliações dos alunos das escolas públicas (SAEB, 1997; ENEM, 1999), a obrigatoriedade de curso universitário para professores (Lei de Diretrizes e Bases no 9.394/96); o exame nacional de egressos dos cursos universitários (Provão (1996-2003) e ENAD, 2004), que trazem novas exigências e deveres sem os concomitantes direitos, contribuem para o desânimo generalizado que reina entre esses profissionais.

Uma das razões para as incertezas do professor face à mudança paradigmática profissional, que coincide com um ambiente de desprestígio e exacerbação dos docentes, é o desconhecimento, por parte do alfabetizador e do professor de língua portuguesa, das teorias de linguagem que embasam os documentos oficiais, pois elas não fazem parte da maioria dos programas dos cursos de Pedagogia e de Letras que os formam (cf. SOARES, 1997). ${ }^{1}$ Acontece, assim, que, previsivelmente, a leitura desses documentos oficiais cuja linguagem não entendem (cf. BORGES DA SILVA, 2003, 2005) e de livros didáticos informados por teorias que desconhecem provoca em muitos deles sentimentos de impotência e frustração (cf. KLEIMAN, 2001, 2003). O próprio governo federal tem interferido na situação, criando, paralelamente à publicação das prescrições, programas de formação de professores (PROFA), publicando volumes de divulgação científica para ensinar os fundamentos teóricos das propostas (Parâmetros em Ação (1999 e 2000),

\footnotetext{
${ }^{1}$ Não é de se estranhar que isso aconteça também com os professores de língua portuguesa, pois, na maioria dos casos, os docentes que atuam no ensino público não são formados nos grandes centros universitários, onde essas teorias são discutidas e ensinadas.
}

KLEIMAN - Os estudos de letramento e a formação... 
por exemplo) e financiando a implantação de uma rede nacional de centros de formação de professores em dezenove universidades do país (REDE, 2004).

Contribuindo para a instabilidade, estão as complexas relações entre o professor e os órgãos que formam e regulam a carreira docente, entre as quais a relação quase simbiótica que existe entre escola e academia, e que se manifesta de maneiras potencialmente empobrecedoras para o professor. Por exemplo, sala de aula, professor, aluno, sua interação e seus textos são, todos eles, separada ou conjuntamente, objeto de constante escrutínio por parte de pesquisadores da universidade, sem que haja um retorno reconhecido como tal pelos professores que, muitas vezes, não prevêem quanto pode ser inquisitiva a pesquisa. Outra manifestação dessa relação é fornecida pela presteza com que teorias sobre a linguagem são adotadas e adaptadas por professores e coordenadores pedagógicos, como foi o caso, na última década, dos estudos do letramento e das teorias de gênero, mesmo quando as teorias estão ainda em elaboração ou quando não são oferecidas como remédio para os males do ensino de português pelos seus proponentes.

Neste trabalho, apresentaremos algumas contribuições dos Estudos do Letramento ${ }^{2}$ - o estudo das práticas relacionadas com a escrita em toda atividade da vida social - para a reflexão sobre a formação do professor de língua escrita na conjuntura aqui especificada. Primeiramente, discutiremos aspectos dessa abordagem, que resguardam o pesquisador do perigo, sempre constante, de seus resultados de pesquisa serem utilizados para reproduzir estereótipos sobre o docente. Em seguida, analisaremos, nos documentos que prescrevem e avaliam as ações do professor, as exigências em relação aos saberes específicos dos

\footnotetext{
2 Defendemos a utilização de Estudos do Letramento, no lugar de Novos Estudos de Letramento, como alguns pesquisadores estão usando. Nos países de língua inglesa, o termo 'literacy' (que hoje devemos traduzir por alfabetização ou letramento, dependendo do contexto) foi mantido pelos pesquisadores que começaram a considerar os aspectos sociais do uso da língua escrita e, face à necessidade de distinguir essa nova perspectiva dos estudos sem a perspectiva social, eles recorreram ao adjetivo 'novos': daí New Studies of Literacy. No Brasil, um novo termo foi cunhado - letramento - pelos pesquisadores que queriam diferenciar os usos da língua escrita na vida social da alfabetização e, assim, os dois termos foram mantidos. No nosso país, portanto, todos os estudos do letramento são novos, datando apenas da década de 90 (cf. KLEIMAN, 1995; SOARES, 1998).
} 
alfabetizadores e professores de língua materna e, finalmente, com base na análise crítica dessas exigências, exploraremos uma alternativa de formação baseada na participação da prática social.

\section{LETRAMENTO NO LOCAL DE TRABALHO}

Desde a década de 70, na mídia, na universidade, nas secretarias de educação, não se questiona apenas a capacidade do docente para ensinar a ler, escrever ou analisar um texto, mas a capacidade de ele próprio conseguir fazer isso, ou seja, sua própria competência lingüístico-enunciativo-discursiva. Não é sua formação o alvo de crítica, mas a sua própria condição de letrado.

O pesquisador interessado na formação do professor, ou no ensino da língua portuguesa, que deseja também posicionar-se criticamente (CAMERON et alii, 1992; KLEIMAN, 2001) face à percepção atual do professor tem, nos paradigmas qualitativos de pesquisa, e, em particular, na abordagem teórica dos Estudos do Letramento, o anteparo e respaldo teórico-metodológico e político que lhe permite desenhar pesquisas que não contribuam para a reprodução dos estereótipos do professor que não conhece a matéria que deve ensinar, não lê nem escreve. Na perspectiva dos Estudos do Letramento, não há apenas uma forma de usar a língua escrita - a reconhecida e legitimada pelas instituições poderosas, à qual poucos têm acesso -, mas há múltiplas formas de usá-la, em práticas diversas que são sociocultural e historicamente determinadas (STREET, 1984; KLEIMAN, 1995; TFOUNI, 1995; SOARES, 1998). Portanto, o argumento não procede.

Os Estudos do Letramento defendem uma concepção pluralista e multicultural das práticas de uso da língua escrita. Sem cair em simplificações que neguem a evidente hierarquização das práticas sociais no nível macroinstitucional, as metodologias etnográficas para a geração de dados, assim como os métodos analíticos dos estudos discursivos (da sociolingüística interacional, da pragmática ou das teorias da enunciação) utilizados nessa abordagem, permitem focalizar atividades situadas, locais, nas quais são construídos contextos sociais em que há distribuição do poder e nos quais podem ser subvertidos - mesmo que 
temporariamente - posicionamentos predeterminados e papéis fixos já institucionalizados (DE CERTEAU, 1994).

Esse olhar microanalítico nos permite entender produções culturais que destituem a validade de diversas racionalizações preconceituosas, as quais justificam o fracasso na escola de grande parcela dos estudantes e o fracasso do professor na realização de sua tarefa. O etnocentrismo perde, assim, sua base racional. De fato, o "modelo ideológico de letramento", descrito por Street (1984), ao levar em conta as situações sociais em que os textos são lidos e produzidos, assim como os valores e as representações a eles atribuídos, acaba destacando os aspectos socioculturais e históricos das práticas de uso da língua escrita e mostrando a necessidade de estudá-las a partir da reconstrução da história e das culturas locais. Seriam os contextos em que as práticas são mobilizadas os que nos mostram as diversas orientações de uso da linguagem, segundo as demandas, objetivos, metas de leitura e escrita das diversas situações de comunicação, assim como das relações, objetivos e necessidades dos participantes dessas situações. O conhecimento dos mundos de letramento (BARTON, 1993), as histórias de leitura (GUEDES PINTO, 2002) dos professores que introduzem o aluno em diversas práticas de uso da língua escrita, parecenos essencial para a universidade formar esses professores para as demandas, também contextualizadas, do mundo do trabalho (KLEIMAN; BORGES DA SILVA, 2008).

Dessa forma, numa sociedade "organizada pelo poder de modificar as coisas e reformar as estruturas a partir de modelos escritos" (DE CERTEAU, 1994, p. 262), a pesquisa informada pelos Estudos do Letramento propicia a observação das estratégias e táticas daqueles que, mesmo participando de forma menos legitimada das práticas sociais letradas, visam também modificar e reformar seu mundo social (cf. VÓVIO, 2007).

\section{PRESCREVENDO E TESTANDO SABERES}

Os saberes necessários para usar a escrita são de fato muitos e diversificados, e ainda mais são aqueles necessários para ensinar esse 
fazer. Dentro desse conjunto, uma questão relevante para a formação do professor, que exploraremos a seguir, é: quais são os conhecimentos especializados que possibilitam uma ação significativa na aula de leitura e produção de textos em língua materna? Em outras palavras, quais são os saberes lingüísticos relevantes para a atuação profissional, para o local de trabalho?

Não há polêmica em relação à centralidade dos conhecimentos específicos - no caso em questão, conhecimentos lingüísticos ${ }^{3}$ - para a formação. O processo de letramento na formação do professor de língua inclui a especificidade da matéria pela qual será responsável na escola. Com propriedade, isso é afirmado no documento parametrizador dos cursos de Letras, a Proposta de Diretrizes Curriculares do Curso de Letras (Parecer CNE/CES 492/2001), que regula os currículos dessa graduação, oferecendo prescrições de ordem geral sobre os conhecimentos de lingüística.

Entretanto, há embutida, nesse documento, uma visão reducionista na própria concepção dos saberes relevantes para a formação do professor de língua materna. Toda concepção que postule uma relação potencializadora entre qualquer teoria, não necessariamente a lingüística, e o ensino é reducionista. No caso da Proposta de Diretrizes Curriculares do Curso de Letras, está aí especificado que a formação profissional deve estar fundamentada em uma "visão crítica das perspectivas teóricas adotadas nas investigações lingüísticas e literárias" e que "os conteúdos caracterizadores básicos devem estar ligados à área dos Estudos Lingüísticos e Literários" (BRASIL, 2001, p. 30).

Apesar da abrangência desse documento regulador quanto aos saberes lingǘsticos (segundo o qual qualquer perspectiva teórica seria válida), se tomamos literalmente a prescrição sobre o currículo, percebemos que uma interpretação da expressão "[...] conteúdos básicos

\footnotetext{
${ }^{3}$ Não estamos advogando uma volta aos argumentos da década de 60 e início da década de 70 sobre as potenciais contribuições da teoria lingüística ao ensino, quando raras vezes eram ouvidas vozes acerca dos limites de tal teoria. Reinava a quase absoluta convicção de que as ciências lingüísticas resolveriam os muitos problemas da humanidade, inclusive os da educação. Uma das poucas vozes discordantes desses preceitos, em 1970, era a de Noam Chomsky, justamente o responsável pela teoria (Gramática Gerativo-Transformacional) que imperava quase que sem oposição nesse momento da história das idéias lingüísticas. Chomsky considerava com ceticismo as possibilidades de contribuição da lingüística para o ensino.
}

KLEIMAN - Os estudos de letramento e a formação... 
ligados à área dos Estudos Lingüísticos [...]” como apenas aqueles conteúdos informados pelos estudos subsidiados pelas teorias lingüisticas não permitiria a realização de um trabalho eficiente no ensino da língua materna.

No ensino da leitura, por exemplo, visto que os textos hoje são multimodais, outros campos da comunicação não verbal têm muito a contribuir para compreender criticamente os textos que nos rodeiam. Embora haja, no campo da Lingüística, concepções de texto ampliadas, tais como as propostas pela Lingüística Textual (KOCH, 1997; MARCUSCHI, 2002), são pouco os lingüistas que, como Gunther Kress (na Inglaterra), têm se ocupado com a 'gramática visual' do texto (KRESS; VAN LEEUWEN, 1996), defendendo que a maior transformação no campo da escrita e do letramento é que "[...] já não podemos mais tratar o letramento (ou a linguagem) como se fosse o único ou o principal ou o mais importante meio de representação e comunicação".

Há muitas outras modalidades hoje (as novas tecnologias facilitam o uso de imagens, sons, na representação da informação), e nos espaços “[...] onde a escrita está inserida, outras modalidades podem ser mais proeminentes e mais significativas". Por isso, o autor defende que as teorias lingüísticas são incapazes de "[...] fornecer uma explicação total do que é e o que faz o letramento; a linguagem por si só não nos pode dar acesso ao significado de uma mensagem constituída de forma multimodal" (KRESS, 2003, p. 35). ${ }^{4}$

Todavia, a Proposta de Diretrizes Curriculares tem também uma perspectiva abrangente, pois ressalta que os conteúdos dos Estudos Lingüísticos e Literários devem, por sua vez, “[...] fundar-se na percepção da língua e da literatura como prática social e como forma mais elaborada das manifestações culturais" (BRASIL, 2001, p.31). Essa prescrição inibe uma interpretação exclusiva de outras abordagens

\footnotetext{
4 " [...] the major change [in the conditions surrounding literacy] is that we can no longer treat literacy (or 'language' as the sole, the main, let alone the major means for representation and communication. Other modes are there as well, and in many environments where writing occurs these other modes may be more prominent and more significant. As a consequence, a linguistic theory cannot provide a full account of what literacy does or is; language alone cannot give us access to the meaning of the multimodally constituted message" (KRESS, 2003, p. 35) (Tradução da autora).
} 
teóricas na formação de professores: se o que está envolvido é o ensino da língua e da literatura "como prática social"; então, os estudos que se preocupam com a descrição de micro-realidades do mundo social (como a Antropologia, a Etnografia, os Estudos do Letramento) aportam perspectivas insubstituíveis para o entendimento do funcionamento da língua na prática social.

Outro documento que indiretamente prescreve as ações do professor é o conjunto de Parâmetros Curriculares Nacionais (PCN). Ele nos informa, de modo mais específico, quais os saberes e capacidades de uso da linguagem (dentre outras competências e objetivos) que se esperam do aluno nos diversos segmentos do Ensino Fundamental e Médio. Se considerarmos esses objetivos de aprendizagem a partir de sua imagem no espelho, da perspectiva do ensino e do professor, podemos inferir, da lista de objetivos e de conteúdos arrolados nos PCN, o que o professor de português tem de saber para poder desenvolver no aluno as capacidades, atitudes e procedimentos de uso da linguagem que o documento considera desejáveis.

Assim, por exemplo, o texto dos PCN para o $2^{\circ}$ ciclo do Ensino Fundamental $\left(5^{\mathrm{a}}\right.$ a $8^{\mathrm{a}}$ séries) afirma, relativamente à produção textual, sem dúvida a mais reflexiva de todas as atividades de linguagem, que se espera que o aluno seja capaz de escrever "[...] textos considerando suas condições de produção: finalidade; especificidade do gênero; lugares preferenciais de circulação; interlocutor eleito" (BRASIL, 1998, p. 59). Isso implica, da perspectiva do ensino, que é relevante, na formação do professor, a capacidade de atualizar, com base na prática social, seus conhecimentos sobre o funcionamento dos gêneros como elementos orientadores da prática de produção textual dos seus alunos. Para fazer isso, o professor precisa de amplos e diversificados conhecimentos lingüísticos, como, por exemplo, sobre o funcionamento dos textos.

De fato, o documento descreve, em continuação, um conjunto bastante extenso de conceitos e procedimentos cujo uso e domínio estariam envolvidos nessa capacidade (de escrever textos adequados às situações em que eles circulam), que abrangem desde procedimentos de textualização, como:

Utilização de mecanismos discursivos e lingüísticos de coerência e coesão textuais, conforme o gênero e os propósitos do texto, 
desenvolvendo diferentes critérios: de manutenção da continuidade do tema e ordenação de suas partes; de seleção apropriada do léxico em função do eixo temático...

até o manejo de convenções notacionais e ortográficas, como:

[...] utilização de marcas de segmentação em função do projeto textual: título e subtítulo; paragrafação; periodização; pontuação (ponto, vírgula, ponto-e-vírgula, dois-pontos, ponto-deexclamação, ponto-de-interrogação, reticências); outros sinais gráficos (aspas, travessão, parênteses). (BRASIL, 1998, p. 59)

A nossa crítica anterior é também pertinente aqui. Há um potencial empobrecimento tanto no Ensino Fundamental quanto, por implicação, no curso de formação devido às limitações da concepção de texto unimodal, obsoleta hoje.

Ainda outro documento interessante para a reflexão sobre a importância relativa dos saberes lingüísticos na formação e atuação do professor é constituído pelas provas de português de concursos de provimento de cargo para professor dessa disciplina, realizadas pelos estados e prefeituras. 5 Essas provas fornecem também indicadores sobre a ação potencializadora dos conhecimentos lingüísticos para a atuação profissional porque, em princípio, as provas a que são submetidos os candidatos perguntariam sobre questões cujas respostas exigem o tipo de conhecimento sobre a linguagem que possibilitaria realizar bem o trabalho de sala de aula. Em outras palavras, as provas identificariam os professores que sabem aquilo que os municípios e os estados consideram importante para a função que aqueles candidatos bem-sucedidos na prova passarão a exercer; daí ser possível afirmar que os concursos estariam testando a competência do profissional, o letramento para o local de trabalho (BORGES DA SILVA, 2005; KLEIMAN; BORGES DA SILVA, 2008).

De fato, a gama de conhecimentos teóricos sobre a língua geralmente testada é bastante ampla nos testes. Selecionamos, para exemplificar essa amplitude e variedade, alguns itens de uma prova

\footnotetext{
5 Outro tipo de prova para finalidade semelhante é o Enad (ou o antigo Provão). Entretanto, o concurso para provimento de cargo estaria especificamente voltado para testar a competência do professor, mais do que o Enad, que testa o aproveitamento (a competência?) do aluno do Curso de Letras.
} 
específica de português de concurso, que testam conhecimentos da Gramática Tradicional, Lingüística Textual e Sociolingüística. ${ }^{6}$ A prova também tinha perguntas sobre Fonologia, Morfologia, Sintaxe (análise sintática) e Semântica.

No exemplo (1), a seguir, os conhecimentos testados são de natureza ortográfica, veiculados pela Gramática Tradicional:

\section{Exemplo (1)}

A formação do plural das palavras terminadas em -r altera o número de sílabas. Assinale a alternativa que não dá conta de nenhuma das formas do português padrão: mares, caracteres $e$ ziperes:

a) o acento permanece no mesmo lugar para garantir o padrão paroxítono

b) o acento pode se deslocar para garantir o padrão oxítono

c) o acento permanece no mesmo lugar, por isso não se mantém o padrão paroxítono

d) o acento pode-se deslocar para garantir o padrão paroxítono

e) o acento permanece no mesmo lugar, ainda que se tenha o padrão proparoxítono

O exemplo (2) refere-se a um item da prova que exige a mobilização de conhecimentos da Lingüística Textual, além de noções sobre textualização da língua oral para a língua escrita:

\section{Exemplo (2)}

[os caras] "botaram a faca... em cima do Zé e pediram todo o din... a renda que ele tinha feito, ... aí ele deu, pediu a chave do carro também aí ele deu, aí mandou ele fazer carreira, ... aí quando chegou aqui próximo do colégio, ... aí os guarda aí da REFESA acho que era a REFESA, avistou e o cara também num sabia dirigir vem aí bateu... por aqui perto, aí eles conseguiram pegar ele" (Aragão e Soares, A linguagem falada em Fortaleza)

\footnotetext{
${ }^{6}$ Prova de Português para Professor de Educação Básica II, Estado de São Paulo, 2003.

KLEIMAN - Os estudos de letramento e a formação...
} 
A transformação do texto falado nos moldes da escrita do português padrão exige algumas operações. Em uma possível transformação do trecho acima, não seria necessário proceder à:

a) reorganização da concordância verbal

b) eliminação de marcas interacionais

c) eliminação de dêiticos

d) reelaboração da pontuação

e) reorganização das relações anáforas

Por último, o exemplo (3) ilustra um tipo de item que exige a mobilização de conhecimentos sobre variação lingüística em conjunção com saberes didático-pedagógicos ou experienciais (TARDIFF, 2002):

\section{Exemplo (3)}

Os dois quadros de Maurício de Sousa exploram a troca do /1/ pelo / r/

\begin{tabular}{|l|}
\hline Cebolinha \\
SEUS DENTES PODELOSOS E \\
AFIADOS VÃO TLITULAR \\
SUA VASSOULA EM \\
SEGUNDOS \\
[quadrinho] \\
\hline
\end{tabular}

Pode se afirmar que:

$$
\begin{aligned}
& \text { Chico Bento } \\
& \text { NuM É DIVERTIDO FAZÊ } \\
& \text { MARVADEZA COS OUTRO! } \\
& \text { [quadrinho] }
\end{aligned}
$$

a) as personagens dominam a mesma variedade lingüística e cabe ao professor ensinar o uso do /1/ no português padrão.

b) as personagens dominam a mesma variedade lingüística e cabe ao fonoaudiólogo ensinar o uso do /1/ no português padrão.

c) as personagens dominam variedades lingüísticas diferentes, mas, em ambos os casos, cabe ao fonoaudiólogo ajudar o falante a recuperar o uso do $/ 1 /$.

d) Chico Bento domina o português popular e deve aprender o português padrão na escola; Cebolinha tem problemas de articulação e deve buscar ajuda de um fonoaudiólogo. 
e) Só um fonoaudiólogo pode ajudar Chico Bento a adquirir o português padrão; Cebolinha deve buscar apoio na escola.

Todos esses exemplos ilustram itens da prova de português que avaliam conhecimentos pertinentes às ciências lingüísticas e sua resolução requer a mobilização de saberes teóricos sobre o funcionamento da língua. Temos de concordar, no entanto, que a demonstração desses conhecimentos na resolução da prova não garante a competência profissional para encaminhar a aula de modo a facilitar, se não garantir, a aprendizagem do aluno e o desenvolvimento de suas capacidades de uso da língua oral e escrita. ${ }^{7}$

Parece, à primeira vista, que a distância entre o conhecimento da teoria lingüística e o conhecimento situado - que envolve a capacidade de mobilizar o saber lingüístico pertinente aos parâmetros da situação comunicativa - estaria encurtada em itens como o do exemplo (3), sobre variedades dialetais e ensino da língua padrão, cuja resolução exige uma combinatória de saberes de referência, no caso (sócio)lingüísticos e saberes didáticos (ou experienciais).

Entretanto, acertar que Chico Bento deve aprender o português padrão na escola não implica saber o que envolve, do ponto de vista identitário, lingüístico e discursivo, ensinar e aprender uma variedade de língua diferente daquela aprendida no seio familiar. No caso relativo à aprendizagem do dialeto padrão da língua, o agir estratégico profissional envolve competências múltiplas, que abrangem desde a capacidade de antecipar o grau de dificuldade dessa aprendizagem, porque resultará numa nova relação com a língua aprendida no lar e transformará relações com outros membros da família, até a capacidade para selecionar leituras e elaborar exercícios, perguntas e outras atividades que favoreçam a aprendizagem e a reflexão do aluno com base no contato com dados pertinentes.

\footnotetext{
${ }^{7}$ Um teste mais dirigido ao local de trabalho distinguiria, provavelmente, entre os conhecimentos de um professor que já refletiu sobre sua prática e os de um aluno de curso de Letras, ou de lingüística, ou fonologia ou de qualquer outra área de conteúdo relevante para a formação. Também podemos imaginar uma prova mais coerente com as teorias atuais sobre a linguagem e o letramento, que não compartimentalize de forma tão marcada as habilidades envolvidas - leitura, escritura e análise lingüística, uma vez que sabemos que todas essas atividades estão envolvidas num evento de letramento.
}

KLEIMAN - Os estudos de letramento e a formação... 


\section{A PRÁTICA SOCIAL}

Para encerrar esta breve discussão sobre os saberes de ordem lingüística na formação do professor para o local de trabalho (ou seja, em relação à viabilização do ensino e da aprendizagem na sala de aula), examinaremos um exemplo que envolve o ensino do gênero 'artigo de opinião’ via seqüência didática. O evento de escritura/produção do texto está situado em uma prática de participação em concurso nacional. ${ }^{8}$ Os participantes, alunos das antigas $4^{\mathrm{a}}$ e $5^{\mathrm{a}}$ séries do Ensino Fundamental, deviam optar por escrever um poema, um relato de memórias ou um artigo de opinião. 9 O grande tema era "O lugar onde eu vivo", e ele determinava o tema específico a ser desenvolvido pelos alunos das turmas participantes. ${ }^{10}$ No caso do artigo de opinião, gênero que focalizaremos, o tema, objeto de uma tomada de posição da turma, teria de estar ligado a uma questão polêmica local, relevante para a vida social do aluno, que dividisse a classe, a escola, o bairro ou a cidade.

Usualmente, os professores que inscreviam suas turmas no concurso recebiam um kit didático de Criação de Texto, visando ao ensino do gênero escolhido. No caso da opção pelo artigo de opinião, trata-se do fascículo Ponto de Vista (GAGLIARDI; AMARAL, 2004), cujos fundamentos teóricos seguem o modelo de seqüência didática, criado por pesquisadores de Genebra para ensino nas escolas da Suíça (DOLZ; SCHNEUWLY, 2004; DOLZ; NOVERRAZ; SCHNEUWLY, 2004; SCHNEUWLY, 2004). O material é imprescindível e altamente pertinente, considerado o baixo número de materiais de divulgação científica para a formação do professor, produzidos no país.

8 O concurso em questão é "Escrevendo o futuro", realizado pelo Centro de Estudos e Pesquisas em Educação (CENPEC) com patrocínio da Fundação Itaú Social. Os dados que apresentaremos referem-se à edição do concurso realizada no ano de 2006. Em 2008, o concurso passou também a ser realizado pelo MEC e faz parte das Olimpíadas de Língua Portuguesa.

$9 \mathrm{Na}$ versão de 2008, cuja realização está em curso, os alunos das $4^{a}$ e $5^{a}$ séries do Ensino Fundamental ( $5^{\circ}$ e $6^{\circ}$ anos do Ensino Básico) devem submeter uma poesia; os alunos das $6^{\mathrm{a}}$ e $7^{\mathrm{a}}$ séries do Ensino Fundamental ( $8^{\circ}$ e $9^{\circ}$ anos do Ensino Básico) devem submeter um relato de memórias e os alunos dos $2^{\circ}$ e $3^{\circ}$ anos do Ensino Médio devem concorrer com um artigo de opinião.

10 A participação era por escola: assim, era escolhido o melhor texto de cada turma e, desses, era escolhido o melhor texto da escola, que passava por sucessivas triagens até chegar à etapa finalista. 
Para o ensino do gênero artigo de opinião, o fascículo propõe a realização de doze oficinas, que abrangem desde os aspectos relativos à situação de comunicação envolvida (identificação de questões polêmicas locais) até a produção final do texto a ser enviado (revisão final), passando por diversas etapas relativas à composição propriamente dita do artigo de opinião (por exemplo, a coleta de opiniões na comunidade, a fim de montar diversos tipos de argumentos). ${ }^{11}$ Além dessas doze oficinas, o fascículo contém textos introdutórios sobre "gêneros textuais e seqüências didáticas" e sobre o artigo de opinião, inclusive com a análise de um exemplar do gênero, com foco na forma em que o texto está estruturado e nos tipos de argumentos que podem ser utilizados. Há também um apêndice com exemplos de artigos de opinião colhidos da imprensa nacional.

A avaliação dos textos submetidos não desconsidera nenhum dos aspectos enfatizados no fascículo. São atribuídos sete pontos aos aspectos macrotextuais ou situacionais: pertinência ao tema proposto (um ponto); presença de elementos da argumentação (três pontos); evidência de que houve busca de informações pertinentes na elaboração do texto (dois pontos) e originalidade dos recursos utilizados (um ponto). São também atribuídos três pontos a aspectos relativos ao domínio das regras gramaticais e ortográficas.

Assim, podemos dizer que é oferecido aos professores cujas turmas participam do concurso um material de suporte de qualidade, informado por teorias adequadas para a descrição textual, a ser usado para o ensino de uma atividade que faz parte (ou deveria fazer) de um evento altamente competitivo, mas também lúdico, com metas bem definidas e agradáveis, promissoras de futuros ganhos e potencialmente enriquecedoras em diversos aspectos. No entanto, tudo isso resulta na

\footnotetext{
${ }^{11}$ As oficinas são as seguintes: 1. Identificando questões polêmicas; 2. Definindo a questão polêmica e escrevendo a produção inicial; 3. Buscando informações; 4. Lendo artigos de opinião; 5. Reconhecendo posições e argumentos favoráveis e contrários; 6. Recolhendo opiniões da comunidade e trabalhando com diferentes tipos de argumentos; 7. Conhecendo elementos articuladores do artigo de opinião; 8. Identificando vozes presentes em um artigo de opinião; 9. Ensaiando a produção de um artigo de opinião; 10. Produção individual; 11. Aprendendo a revisar um texto e 12. Produção final (GAGLIARDI; AMARAL, 2004).
}

KLEIMAN - Os estudos de letramento e a formação... 
produção majoritária de textos que não são artigos de opinião, mas exposições de problemas, conforme exemplificado a seguir. ${ }^{12}$

\section{Exemplo (4)}

\section{O lixão}

O lixão de I (nome da cidade) está localizado na vila SM (nome do bairro), ele é o lugar onde todo o lixo de I é colocado, as pessoas que moram lá catam comida estragada, roupa rasgada, tem criança que entra no lixão e pega muitas doenças.

$\mathrm{Na}$ minha opinião algumas providencias deveriam ser tomadas, pro exemplo: tira-lo de lá transferindo para um outro local distante da população ou fecha-lo, pois o lixão não traz benefícios para quem mora no bairro SM.

Algumas pessoas são contra a retirada, outras são a favor, eu sou a favor. O lixão é muito perigoso, por isso a prefeitura deveria tomar uma providência rápida, pois o lixão pode causar contaminação e até matar.

Vejamos mais um exemplo, também com a mesma organização: apresentação do problema, opinião pessoal, opiniões de outros, solução.

Exemplo (5)

Água é vida

A população de CBV (nome do bairro) está crescendo cada vez mais e as pessoas estão sendo prejudicadas pelo consumo da água que não está sendo suficiente para todos.

Do meu ponto de vista, a comunidade precisa de uma caixa d'água bem maior, para que esta água chegue em todas as casas. No momento não está atendendo as necessidades de todas as famílias. Umas famílias são beneficiadas e outras não.

A caixa d'água e motores que temos estão sendo pequenos para o abastecimento de nossa água.

${ }^{12}$ Textos como os dos exemplos constituem quase a metade (43\%) de uma amostra aleatória de 160 textos. 
Algumas pessoas discordam, acham que não é necessário aumentar a caixa d'água e o que deve fazer é comprar outros motores mais potentes. E assim acabaria essa falta de água em algumas famílias.

Por isso, não podemos deixar que este problema se agrave cada vez mais. Chega de tanto sofrimento. Precisamos dessa água, pois necessitamos dela para vivermos.

Vale lembrar que redações 13 como (4) e (5) são as que já passaram pelo menos por duas seleções: a melhor da turma e, subseqüentemente, a melhor da escola. As óbvias dificuldades composicionais de ambos os textos e o fato de o artigo de opinião ser o gênero menos escolhido no concurso são índices da pouca familiaridade do aluno com o gênero (e, por extensão, da menor familiaridade do professor com situações de ensino desse gênero). Daí a dimensão que adquire, na elaboração dos textos desse gênero, o material de suporte para o professor.

$\mathrm{O}$ artigo de opinião é de recente introdução no repertório escolar (SOUZA, 2003) e sua complexidade é grande devido, principalmente, à natureza da argumentação nos textos do gênero, baseada no exercício racional, e não no apelo emocional. Por isso, o material produzido para a formação do professor é elemento marcante na atuação do professor: veremos que há intertextualidade explícita na construção dos textos, particularmente nos modos de introduzir diversas vozes e nos modos de introduzir a própria voz.

O modelo didático fornecido no fascículo é imitado em vários momentos nos dois exemplos. $\mathrm{Na}$ análise de um dos exemplos de artigo de opinião fornecido como exemplar para a análise e como modelo, o fascículo aponta que "nos dois primeiros parágrafos, a autora localiza o leitor em relação ao fato que provocou a discussão na cidade" e os textos (4) e (5) fazem isso no primeiro parágrafo. O fascículo destaca, ao apresentar seu modelo, que “com a expressão 'Eu penso que...', a autora toma uma posição em relação à questão polêmica" (GAGLIARDI; AMARAL, 2004; p. 27) e ambos os textos analisados marcam os

${ }^{13}$ Já que se trata de produção de redação, não de artigo de opinião, nem de artigo de opinião escolar (BALTAR, 2006).

KLEIMAN - Os estudos de letramento e a formação... 
posicionamentos do autor por meio das frases "Na minha opinião"; “eu sou a favor"; "do meu ponto de vista". ${ }^{14}$

Também o fascículo descreve, a respeito de um texto fornecido como modelo para análise, que "[...] no terceiro parágrafo, a autora traz os argumentos daqueles que são contra..." e os textos acatam isso como sugestão, inclusive utilizando expressões recomendadas para introduzir e articular outras vozes. Assim, o modelo sugere que, "[...] quando os alunos forem escrever seu artigo de opinião, precisarão de expressões como estas para poder introduzir as vozes que circulam sobre a questão polêmica escolhida" e logo exemplificam: "Alguns acham que não...; Há pessoas que são contra...; Outras são a favor...” (p. 35) e, nos textos (4) e (5) produzidos pelos participantes do concurso encontramos praticamente as mesmas expressões para o gerenciamento de vozes diferentes da voz do enunciador: "Algumas pessoas são contra a retirada, outras são a favor"; "Algumas pessoas discordam, acham que não é necessário".

O fascículo mostra ainda como articular argumentos e, nos dois exemplares de textos elaborados pelos alunos, encontramos o uso dos articuladores sugeridos no fascículo para tal fim: "O lixão é muito perigoso, por isso a prefeitura deveria tomar uma providência, pois o lixão pode causar contaminação e até matar"; "Por isso, não podemos deixar que este problema se agrave..."; "Precisamos dessa água, pois necessitamos dela...".

Aspectos relevantes da situação comunicativa são igualmente destacados no fascículo, que frisa, repetidas vezes, a importância da identificação de uma questão polêmica, de buscar dados para sustentar as opiniões defendidas e de identificar argumentos tanto favoráveis como contrários à posição assumida. Entretanto, esses aspectos foram ignorados. Utilizando a perspectiva dos autores da escola de Genebra, cuja teoria inspirou o modelo apresentado no fascículo, diríamos que essas produções envolveram efetivamente as operações de gestão e linearização textuais, mas que a base de orientação - a produção de parâmetros que orientem a produção textual segundo as coordenadas da

\footnotetext{
${ }^{14} \mathrm{O}$ fascículo sugere outras formas de modalização, que inspiraram os textos em questão. Por exemplo, a frase "minha opinião" é a resposta dada à seguinte pergunta, na p. 30: "quais palavras que marcam a tomada de posição?".
} 
situação social - não foi uma operação bem-sucedida (SCHNEUWLY, 1997; MATENCIO, 2003). Daí que, apesar de terem seguido os aspectos formais do modelo fornecido, os textos não são artigos de opinião.

O descompasso entre o ensino pretendido e o realizado diz respeito à complexidade de uma situação de uso da língua escrita que considera, em primeiro plano, a situação de comunicação e que extravasa, por isso, o escopo das análises dos também complexos aspectos textuais (do gênero em questão), que são passíveis de teorização lingüística e textual-enunciativa (e o tem sido tradicionalmente). Os exemplos analisados nos mostram que o ato de escrever, ou a solicitação para que se escreva um artigo de opinião (ou um poema ou um relato de memórias) é ressignificado na escola em função do produto (nesse caso, coincidente com o interesse do concurso).

Um texto pertence ao gênero artigo de opinião quando os elementos enunciativo-discursivos (ou retóricos, segundo alguns autores, como VIGNER, 1987) e os aspectos composicionais e estilísticos se complementam. Entretanto, esses aspectos não confluem nos textos em exame, marcados por uma hibridização que parece ser resultante de distintos condicionantes da situação social: os da situação escolar do aluno (e do professor), o qual procura adequar seu texto às exigências do concurso, e os da vida cotidiana desse mesmo aluno, que é vítima do lixo exposto ou da falta de água.

Essa hibridização se manifesta, por um lado, nas expressões reguladoras que recomendam ou sugerem ações ("a prefeitura deveria tomar uma providência rápida”) ou que exortam para a ação (“...não podemos deixar que este problema se agrave cada vez mais. Chega de tanto sofrimento") e, por outro, nas expressões próprias dos textos opinativos que indiciam uma tomada de posição sobre o problema do lixo ou da falta d'água ("Na minha opinião", "eu sou a favor", "do meu ponto de vista"); porém, sem mobilizar argumentos que convençam o leitor pela sua racionalidade e sua lógica, que são, por convenção, mais eficazes nos textos desse gênero.

Lembremos que o estilo de um gênero, para Bakhtin (1997), decorre da presença de recursos da língua que organizam, enquadram e salientam a posição enunciativa do autor: nos textos analisados, os recursos pertencem à modalização lógica, própria do estilo do artigo de 
opinião, intercalados com recursos da modalização deôntica, própria da exortação, do apelo ao bom senso ou aos sentimentos.

Cria-se, por meio de palavras que indiciam uma tomada de posição, um efeito argumentativo, mas não há evidências de acento valorativo nessas palavras, isto é, não há evidências do trabalho do aluno enunciador de convencer um grande auditório nacional sobre a legitimidade, a pertinência, ou a justeza da sua posição sobre o assunto em debate, o que determinaria a mobilização e a organização dos argumentos.

Pelo contrário, o uso dos elementos formais de seqüenciamento e coesão dos textos do gênero, em textos híbridos que mostram sobreposição (mas não integração) dos discursos, indica a necessidade de usá-los para satisfazer os eventuais avaliadores no concurso nacional. Em outras palavras, os operadores argumentativos do texto não são utilizados para mobilizar as evidências necessárias para sustentar uma determinada opinião. Eles estão no texto como evidência de que o fascículo que ensina o gênero foi lido, ou debatido, ou é conhecido.

Isso mostra que esses enunciadores não estão servindo-se “[...] da língua para suas necessidades enunciativas concretas" (VOLOSHINOV/BAKHTIN, 1979, p. 78). Ao contrário do que Voloshinov/Bakhtin afirmam em relação aos usos da língua, para esses alunos e seus professores o "centro de gravidade da língua" reside "na conformidade à norma da forma utilizada" (p.78).

Segundo Voloshinov/Bakhtin, na situação de comunicação concreta,

O que importa não é o aspecto da forma lingüística que, em qualquer caso em que esta é utilizada, permanece sempre idêntico. Não; para o locutor o que importa é aquilo que permite que a forma lingüística figure num dado contexto, aquilo que a torna um signo adequado às condições de uma situação concreta dada. Para o locutor, a forma lingüística não tem importância enquanto sinal estável e sempre igual a si mesmo, mas somente enquanto signo sempre variável e flexível. (1979, p. 78-79)

Quanto aos recursos lingüísticos que foram objeto de ensino, não podemos dizer que os textos dos quais (4) e (5) são amostras constituem evidência de que houve "compreensão da palavra no seu sentido 
particular, isto é, a apreensão da orientação que é conferida à palavra por um contexto e uma situação precisos" (VOLOSHINOV/ BAKHTIN, 1979, p. 80).

É assim que o espaço dado a outras vozes no artigo de opinião, para posteriormente refutá-las, aparece nos textos escolares como a descrição de opiniões diferentes, inacabadas e ineficazes porque se espera em vão a apresentação de contra-argumentos: "Algumas pessoas são contra a retirada, outras são a favor, eu sou a favor." "Algumas pessoas discordam, acham que não é necessário aumentar a caixa d'água...". É assim, também, que procuramos em vão pelo movimento de acordo ou desacordo que está sempre presente no uso concreto da linguagem, segundo Voloshinov/ Bakhtin (1979, p. 92): “[...] toda enunciação efetiva, seja qual for sua forma, contém sempre, com maior ou menor nitidez, a indicação de um acordo ou de um desacordo com alguma coisa".

É também por essa razão que, no primeiro parágrafo do texto (4), no lugar de uma tomada de posição firme e clara, encontramos uma descrição do lugar e uma incipiente problematização: "O lixão de Ixxx está localizado na vila SM, ele é o lugar onde todo o lixo é colocado, as pessoas que moram lá catam comida, roupa rasgada, tem criança que entra no lixão e pega muita doença.”. E, por último, é assim também que a tomada de posição, nos dois exemplos no segundo parágrafo, não está suficientemente indiciada nos textos, restringindo-se à manifestação de uma opinião sobre o fato relatado, sinalizada pelas expressões "na minha opinião" e "do meu ponto de vista", sem, porém, um acento avaliativo, isto é, a presença de palavras que expressem a apreciação valorativa do aluno em relação ao tema desenvolvido. Falta a indignação, a força e o envolvimento da modalização apreciativa, que sinaliza a defesa de uma posição, a qual só emerge no final dos dois textos em análise: "o lixão é muito perigoso", "chega de tanto sofrimento". Uma espécie de coda na qual o aluno se permite enunciar palavras dotadas de significação.

Concluímos, com base nos dados, que os textos que são produto dessa situação nos mostram os limites da dimensão lingǘ́stica e enunciativa. Por mais relevante que seja a teoria adotada, o trabalho 
docente envolve, acreditamos, uma outra dimensão: a social e agentiva, voltada para a ação, pela linguagem, na prática social. ${ }^{15}$

No caso analisado, a ação teria de ter sido, de fato, tomar e defender uma posição, em vez de simplesmente escrever um texto do gênero artigo de opinião. Saber quando e em que condições se produz um texto de determinado gênero, ou como se estrutura um texto do gênero artigo de opinião, por exemplo, ou quais são alguns de seus aspectos estilísticos, não implica, de modo algum, saber como ensinar esse gênero (nem, aliás, saber escrever textos do gênero).

Isso, no entanto, não significa que devamos concluir que o conhecimento de uma teoria atualizada e de grande poder explicativo seja desnecessário e que, por extensão, o fascículo seja desnecessário. ${ }^{16}$ Os exemplos analisados mostram as limitações desse saber, que decorrem, em parte, das características da escola e de suas práticas de letramento, que favorecem os fazeres analíticos em detrimento da prática situada.

Cabe aqui a observação sobre a escola feita em relação ao ensino de língua materna a jovens do Ensino Médio: "[...] numa instituição que prioriza as atividades analíticas, a elevação do gênero a elemento estruturante do currículo pode resultar na sobreposição de mais um

\footnotetext{
${ }^{15} \mathrm{Na}$ abordagem aos gêneros da linha da Nova Retórica, autores como Miller propõem analisar os gêneros como fenômenos sociais; eles são definidos levando em conta, entre outros elementos, os parâmetros da ação social que o gênero permite realizar em situações específicas. Para a autora (1984, p. 159-163), o gênero é uma ação retórica tipificada baseada em situações sociais recorrentes. Também para Bazerman a situação social, da qual o gênero emerge, é, ao mesmo tempo, criada pelo próprio gênero; o gênero é fato social que define e modula o discurso em diversas realidades. Segundo o autor, as "tentativas de estudar os gêneros através dos textos do gênero não são produtivas porque tratam categorias socialmente construídas como fatos estáveis ".attempts to understand genre by the texts themselves are bound to fail because they treat socially constructed categories as stable natural facts") (1988, p. 7-8). Para esses autores, uma questão relevante para o ensino é determinar, a partir da realidade social dos alunos (extração social, por exemplo) quais gêneros ensinar: “ ... quais gêneros funcionam em sala de aula vai depender de uma negociação entre as instituições, o professor e os alunos" (BAZERMAN, 2006, p. 33). Na nossa perspectiva, no entanto, a questão não é apenas sobre os relativos méritos de uma posição formalista versus uma posição socioconstrucionista; a questão relevante é determinar, a partir da realidade social do aluno, qual é a atividade que o moverá, para, somente então, definir quais são os gêneros que serão abordados para o grupo poder agir nas situações sociais criadas em função da consecução das atividades.

${ }_{16}$ Aliás, a revista da organização publica artigos de opinião bem-sucedidos, produzidos por alunos participantes do concurso, que são excelentes exemplos de artigos de opinião sobre assuntos relevantes para o tecido social.
} 
conjunto de descrições metalingüísticas a ser aprendido, em vez de resultar numa matriz sócio-histórica [o gênero] que guie as ações dos jovens" (KLEIMAN, 2006, p. 33).

O que significa, em relação aos usos da linguagem, estruturar o ensino com base na prática social e como isso se diferencia do ensino estruturado em torno dos gêneros relevantes para participar da prática social? Nos dois casos, o objetivo das atividades de ensino-aprendizagem é o ensino de gênero; contudo, faz sentido a didatização desse objetivo, em última instância lingüístico, na escola de ensino fundamental e médio, cujo objetivo maior é a formação de usuários autônomos e competentes da língua escrita. A estruturação do ensino em torno da prática social é uma estratégia de didatização que, na nossa experiência, tem se mostrado eficiente e relevante na formação de professores, fornecendo um modelo que pode, depois, ser recontextualizado pelo professor na sua esfera de atividade, do ensino escolar.

Quando a prática social estrutura as atividades da sala de aula, o eixo do planejamento é a ação. Se, como no exemplo, o assunto que afeta a turma é a presença do lixão no bairro, há necessidade de definir, com os alunos, o que pode ser feito pelo grupo a respeito: uma campanha, para pressionar o poder público ou para mobilizar os moradores, está dentro das possibilidades de uma classe e certamente envolverá elaborar cartazes, entrevistar pessoas da comunidade, escrever cartas abertas, abaixo-assinados, inclusive artigos de opinião. É a necessidade de agir o que determina o gênero a ser mobilizado e, portanto, ensinado, não vice-versa. Quando se age pela linguagem em diversas situações sociais, os gêneros são mobilizados segundo necessidades imediatas de comunicação, assim como segundo determinantes macrossociais. E, de fato, a familiaridade com outros gêneros pode ser necessária para ter bons argumentos e, assim, escrever um bom artigo de opinião sobre o assunto que mobiliza a comunidade local ${ }^{17}$, mas o objetivo dessas diversas ações não deveria ser a obtenção de bons argumentos para o artigo de opinião, mas a atividade, seja ela uma mobilização dentro da sala de aula, da escola, do bairro ou da cidade.

\footnotetext{
17 O fascículo de Gagliardi e Amaral (2004) propõe atividades tais como entrevistas para conhecer outros posicionamentos sobre o debate tema do artigo de opinião.
}

KLEIMAN - Os estudos de letramento e a formação... 
Em um curso de Letras para professores com larga experiência em sala de aula, Tinoco (2008) desenvolve uma proposta de estágio supervisionado que correlaciona o curso de formação e as turmas de educação básica dos professores em formação em torno da atividade de participação no concurso Tesouros do Brasil. Nesse trabalho, que a autora descreve como formação via projetos de letramento ${ }^{18}$, uma das primeiras mudanças nas aulas desses professores é "[...] a abertura para mudanças no percurso, a flexibilidade das etapas de trabalho e o aproveitamento de oportunidades" (TINOCO, 2008, p. 162).

Segundo Tinoco, não havendo uma seleção prévia do gênero a ser ensinado, o plano geral de atividades para dar conta do projeto (e assim poder submetê-lo ao concurso) passa a ser central. Atividades - ao contrário dos objetivos, que continuam sendo os mesmos - podem ser ajustadas ao longo do processo justamente para atingir objetivos que valem a pena. Não há risco de algum elemento do currículo ficar de fora, porque a aprendizagem de leitura e de produção de qualquer texto de qualquer gênero da escrita sempre envolve capacidades de articular o gênero à situação social e capacidades de textualização para agir e fazer sentido por meio da escrita. Essas capacidades constituem, em última instância, o objetivo final de todo programa de letramento escolar.

Os conteúdos necessários para atingir essa competência (estratégias, procedimentos, saberes conceituais) continuam sendo alvo do ensino, mas não estruturam as atividades: ir da prática social ao conteúdo (cf. KLEIMAN, 2007) faz muito mais sentido porque permite que os alunos inscrevam suas vozes na atividade (cf. TINOCO, 2008): o desconhecimento do gênero numa situação de aprendizagem formal pode resultar, como nos exemplos analisados, no revozeamento da palavra de autoridade, num texto dirigido ao professor. ${ }^{19}$ Não temos,

${ }^{18}$ Um projeto de letramento se constitui como "um conjunto de atividades que se origina de um interesse real na vida dos alunos e cuja realização envolve o uso da escrita, isto é, a leitura de textos que, de fato, circulam na sociedade e a produção de textos que serão realmente lidos, em um trabalho coletivo de alunos e professor, cada um segundo sua capacidade" (KLEIMAN 2000, p. 238). Independentemente do tema ou do objetivo do projeto, ele é adequado na medida de seu potencial para mobilizar conhecimentos, experiências, capacidades, estratégias, recursos, materiais e tecnologias em situações concretas de uso da língua escrita de interesse do aluno.

19 Palavra de autoridade é aquela que "permanece nitidamente demarcada, compacta e inerte: exige, por assim dizer, não somente aspas mas uma demarcação ainda mais magistral, um roteiro especial, por exemplo". Bakhtin (2004) afirma também que o discurso de autoridade não permite nenhum jogo com o contexto que a emoldura, nenhum jogo com suas fronteiras, nenhuma 
nesse caso, o resultado de uma aprendizagem na qual "a situação social mais imediata e o meio social mais amplo determinam, completamente e, por assim dizer, a partir de seu próprio interior, a estrutura da enunciação" (VOLOSHINOV/BAKHTIN, 1979, p. 99). 20 Temos, nos textos analisados, a "enunciação isolada-fechada-monológica, desvinculada de seu contexto lingüístico e real...” (p. 85). ${ }^{21}$

Daí a importância da inserção dos alunos de cursos de Letras e Pedagogia, futuros professores de língua escrita, na prática social acadêmica, quando estão na universidade, e da exploração e resgate das práticas de letramento nas atividades de seu cotidiano doméstico, burocrático, médico, religioso. As atividades analíticas que constituem as práticas situadas no curso de formação seguem a ação social, voltada para o letramento para o local de trabalho.

Não é o conhecimento de uma determinada teoria, por mais recente ou por maior que seja seu poder ou sua eficácia para explicar os fenômenos da linguagem, o que faz do alfabetizador ou do professor de língua materna um profissional bem formado na sua área. ${ }^{22} \mathrm{Um}$ novo saber pode ser aprendido pelo professor que transita tranqüilamente pela prática de leitura de textos acadêmicos, ou de divulgação científica ${ }^{23}$, ou de análise do livro didático, ou que consegue coordenar um projeto pedagógico (cf. TINOCO, 2008), enfim, pela via da ação em diversas práticas sociais.

\footnotetext{
transição gradual e flexível, nenhuma variante espontânea do estilo"; enfim, aquela que deve ser "ou totalmente assumida ou totalmente rejeitada". Tradução da autora de: "[...] it remains sharply demarcated, compact and inert: it demands, so to speak, not only quotation marks but a demarcation even more magisterial, a special script, for instance. [...[ authoritative discourse permits no play with the context framing it, no play with its borders, no gradual and flexible transitions, no spontaneously creative stylizing variables of it"; $[\ldots]$ one must either totally affirm it, or totally reject it”. [...] (BAKHTIN, 2004, p. 343)

${ }^{20}$ Itálicos no original da tradução brasileira.

${ }^{21}$ Itálicos no original da tradução brasileira.

22 Até porque é próprio da prática de pesquisa estar em constante busca de teorias que, devido ao seu maior poder explicativo, superem a atual.

${ }^{23}$ Estamos fazendo uma diferença entre os gêneros que têm por objetivo a formação profissional, a introdução do aluno universitário aos princípios de determinada ciência (pertencentes ao discurso de semidivulgação científica, segundo Loffler-Laurian (1984)), e aqueles que têm por objetivo a divulgação para o grande público dos resultados científicos recentes mais interessantes para o homem comum, próprios da esfera jornalística.
}

KLEIMAN - Os estudos de letramento e a formação... 


\section{CONSIDERAÇÕES FINAIS}

A exploração dos limites e potencialidades dos saberes sobre a linguagem culminou com a proposta de um princípio organizador dos currículos, tanto na universidade, nos cursos de formação do professor, quanto na escola, nas aulas para aprender a ler e escrever textos de diversos gêneros: o elemento estruturante do currículo e, portanto, do ensino seria a prática social e não o construto formal teórico, seja ele textual, enunciativo ou discursivo. Delineia-se, assim, uma outra dimensão dos Estudos do Letramento: a do seu impacto na educação. ${ }^{24}$

Tal impacto está muito evidente em relação ao processo de alfabetização nos primeiros anos escolares, tendo até inspirado novas abordagens para o ensino da língua escrita. Embora não acreditemos nas relações diretas algumas vezes propostas entre letramento e método, que nos parecem, no mínimo, questionáveis, acreditamos que assumir a perspectiva sócio-histórica e cultural da escrita acarreta a reorganização do ensino - na universidade ou na escola - em torno da prática social. O impacto dessa transformação, se um dia ela vier a acontecer, é imponderável.

Os saberes envolvidos na atuação docente são situados: eles envolvem estratégias de ação pela linguagem, adquiridas na e pela prática social. Eles estão relacionados com habilidades para usar códigos, com técnicas de leitura e de escrita e com conhecimentos teóricos sobre textos, estilo e gêneros e, acima de tudo, com a prática social de uso da linguagem (tanto práticas orais como escritas), isto é: com estratégias e modos de acessar diversos mundos culturais, de comunicar-se com o outro, através de diversas linguagens, de mobilizar modelos sociocognitivos, interativos (por exemplo, gêneros) que permitam aos alunos alcançar suas metas, para eles se comunicarem, acessarem seus recursos culturais, brincarem, experimentarem novas situações, enfim, para aprenderem o que vale a pena aprender.

Tudo isso faz parte do letramento para/no local de trabalho. A formação do professor é uma construção pessoal, decorrente do conhecimento teórico da matéria, do conhecimento sobre os métodos e

\footnotetext{
${ }^{24}$ Perspectiva denominada letramento curricular por Bunzen (em andamento).
} 
modos de ensiná-la e das suas experiências (TARDIF, 2002) ${ }^{25}$, o que certamente inclui experiências didáticas anteriores que o ajudam a determinar, em uma nova situação, como diagnosticar, avaliar e decidir um curso de ação.

Além dos conhecimentos teóricos pertinentes, devidamente ressignificados para a situação de ensino, o letramento para o local de trabalho abrange também conhecimentos sobre as condições específicas de trabalho, as capacidades e interesses da turma, a disponibilidade de materiais e o acesso que a comunidade tem a eles. E, nesse sentido, quanto mais o docente souber sobre o objeto de estudo e a situação comunicativa envolvida, sobre seus alunos e sua bagagem cultural, maiores serão as probabilidades de ele ser capaz de criar situações significativas de aprendizagem.

Um dos aspectos necessários do processo envolve, então, a ação de um docente que busca desenvolver, cotidianamente, estratégias que lhe permitam a necessária autonomia para transitar de uma prática a outra, com segurança, não pelo fato de já conhecer todos os potenciais gêneros com que irá se deparar numa situação comunicativa qualquer, mas porque pode mobilizar as capacidades, recursos, tecnologias que conhece de outras situações para essa nova situação e, assim, continuar seu processo de letramento ao longo da vida.

Assim, acreditamos ser possível dizer que é o professor familiarizado com as práticas de letramento acadêmicas (entre outras) quem determina quais são os limites e as possibilidades dos saberes teóricos que subsidiam sua disciplina de ensino. Sem os demais saberes, perceberá constantemente os limites dos saberes especializados; munido de outros saberes, multiplicará as possibilidades acenadas pelo saber teórico, em função da segurança decorrente de seu conhecimento sobre o funcionamento da linguagem. Portanto, em última instância, somos nós, os formadores dos professores, que demarcamos os limites, mas, sobretudo, as interfaces potencializadoras dos saberes teóricos e a prática social no ensino da língua escrita.

25 Tardif (2002, p. 48) distingue, na sua análise dos saberes do professor, os saberes experienciais, que seriam saberes práticos, aqueles que são "atualizados, adquiridos e necessários no âmbito da prática da profissão docente".

KLEIMAN - Os estudos de letramento e a formação... 


\section{REFERÊNCIAS}

BALTAR, M. Competência discursiva e gêneros textuais: uma experiência com o jornal em sala de aula. Caxias do Sul: EDUCS, 2006.

BAKHTIN, M. Discourse in the novel. In: . The dialogic imagination. Ed. by M. Holquist; transl. by Carly Emerson and Michael Holquist. Austin: University of Texas Press, 2004.

. Os gêneros do discurso. In: ed. São Paulo: Martins Fontes, 1997. p. 277-326. . Estética da criação verbal. 2. BARTON, D.; HAMILTON, M. Worlds of literacy. Clevedon: Multilingual Matters, 1993.

BAZERMAN, C. Shaping written knowledge: the genre and activity of the experimental article in science. Madison, Wisconsin: The University of Wisconsin Press, 1988.

Gênero, agência e escrita. Organizado por Judith C. Hoffnagel e Angela P. Dionísio. São Paulo: Cortez Editora, 2006.

BORGES DA SILVA, S. Seleção de professores: análise crítica de uma prova de concurso. ALED, 2005, Atas do Congresso... Disponível em:

<http://www.congressoaled2005.puc.cl/pdf/borges.pdf >.

BRASIL. MEC. Parâmetros curriculares nacionais de língua portuguesa. Terceiro e quarto ciclos do Ensino Fundamental. Brasília: MEC/SEF, 1998.

. MEC. Diretrizes curriculares para os cursos de Letras. (Parecer CNE/CES492/2001). Brasília, 2001.

BUNZEN, C. Um estudo sobre a recepção do gênero livro didático de língua portuguesa: implicações para a formação do professor. Tese (Doutorado em Lingüística Aplicada) - Instituto de Estudos da Linguagem, Universidade Estadual de Campinas. (em andamento)

CAMERON, D.; FRAZER, E.; HARVEY, P.; RAMPTON, M.B.H.;

RICHARDSON, K. Researching language: issues of power and method. London: Routledge, 1992.

DE CERTEAU, M. A invenção do cotidiano: artes de fazer. Rio de Janeiro: Vozes, 1994. 
DOLZ, J.; NOVERRAZ, M.; SCHNEUWLY, B. Seqüências didáticas para o oral e a escrita: apresentação de um procedimento. In: SCHNEUWLY, B.; DOLZ, J.; e colaboradores. Gêneros orais e escritos na escola. Organização de R. H. R Rojo. Campinas: Mercado de Letras, 2004. p.95-128.

; SCHNEUWLY, B. Gêneros e progressão em expressão oral e escrita. Elementos para reflexões sobre uma experiência suíça (francófona). In: SCHNEUWLY, B.; DOLZ, J.; e colaboradores. Gêneros orais e escritos na escola. Organização de R. H. R Rojo. Campinas: Mercado de Letras, 2004. p. 41-70.

GAGLiARDI, E.; AMARAL, H. Pontos de vista. Coordenação técnica Centro de Estudos e Pesquisas em Educação, Cultura e Ação Comunitária. São Paulo: Peirópolis, 2004.

\section{GUEDES-PINTO, A. L. Rememorando trajetórias da professora-}

alfabetizadora: a leitura como prática constitutiva de sua identidade e formação profissionais. Campinas: Mercado de Letras; Faep/Unicamp; São Paulo: Fapesp, 2002.

KLEIMAN, A. B. Modelos de letramento e as práticas de alfabetização na escola. In: KLEIMAN, A. B. (Org.). Os significados do letramento: uma nova perspectiva sobre a prática social da escrita. Campinas, SP: Mercado de Letras, 1995. p. 15-61.

O processo de aculturação pela escrita: ensino da forma ou aprendizagem da função? In: KLEIMAN, A. B.; SIGNORINI, I. (Orgs.). O ensino e a formação do professor: alfabetização de jovens e adultos. Porto Alegre: Artmed, 2000. p. 223-243.

Letramento e formação do professor: quais as práticas e exigências no local de trabalho? In: KLEIMAN, A. B. (Org.). A formação do professor: perspectivas da Lingüística Aplicada. Campinas: Mercado de Letras, 2001. p. 3968.

Leitura e prática social no desenvolvimento de competências no ensino médio. In: BUNZEN, C.; MENDONÇA, M. (Orgs.). Português no ensino médio e formação do professor. São Paulo: Parábola Editorial, 2006. p. 23-36.

Letramento e suas implicações para o ensino de língua materna. Signo, Santa Cruz do Sul, v. 32, n. 53, p. 1-25, dez. 2007b.

; BORGES DA SILVA, S. B. Letramento no local de trabalho: o professor e seus conhecimentos. In: OLIVEIRA, M. S.; KLEIMAN, A. B. 
(Orgs.). Letramentos múltiplos: práticas, instrumentos e representações. Natal: Editora de UFRN, 2008.

KOCH, I. V. O texto e a construção dos sentidos. São Paulo: Contexto, 1997.

KRESS, G. R. Literacy in the New Media Age. London: Routledge, 2003.

; VAN LEEUWEN, T. Reading images: the grammar of graphic design. London: Routledge, 1996.

LOFFLER-LAURIAN, A. M. Typologie des discours scientifiques: deux approches. Études de Linguistique Appliquée, n. 51, p. 8-20, 1983.

MARCUSCHI, L. A. Gêneros textuais: definição e funcionalidade. In: DIONISIO, A. P.; MACHADO, A. R.; BEZERRA, M. A. (Orgs.). Gêneros textuais e ensino. Rio de Janeiro: Lucerna, 2002.

MATENCIO, M. L. M. O estudo dos gêneros do discurso: notas sobre as contribuições do interacionismo. In: MACHADO, I. L.; MELLO, R. (Orgs.). Gêneros: reflexões em análise do discurso. Belo Horizonte:

NADE/FALE/UFMG, 2004. p. 221-231.

MILLER, C. R. Genre as social action. In: FREEDMAN, A.; MEDWAY, P. (Orgs.). Genre and the new Rhetoric. London: Taylor and Francis, 1984. p. 151-167.

SOARES, M. B. Sobre os PCN de Língua Portuguesa: algumas anotações. In: MARCUSCHI, E.; SOARES, E. A. L. (Orgs.). Avaliação educacional e currículo: inclusão e pluralidade. Recife: Editora Universitária da UFPE, 1997. 1998. . Letramento: um tema em três gêneros. Belo Horizonte: Autêntica,

SOUZA, L. V. As proezas das crianças em textos de opinião. Campinas, Mercado de Letras, 2003.

STREET, B.V. Literacy in theory and practice. Cambridge: Cambridge University Press. 1984.

SCHNEUWLY, B. Gêneros e tipos de discurso: considerações psicológicas e ontogenéticas. In: SCHNEUWLY, B.; DOLZ, J.; e colaboradores. Gêneros orais e escritos na escola. Organização de R. H. R Rojo. Campinas: Mercado de Letras, 2004. p. 95-128. p. 21-40.

TARDIF, M. Saberes docentes e formação profissional. Petrópolis, RJ: Vozes, 2002. 
TFOUNI, L. V. Letramento e alfabetização. São Paulo: Cortez Editora, 1995.

TINOCO, G. M. A. M. Projetos de letramento: ação e formação de professores de língua materna. Tese (Doutorado em Lingüística Aplicada) Instituto de Estudos da Linguagem, Universidade Estadual de Campinas, 2008.

VIGNER, G. Técnicas de aprendizagem da argumentação escrita. In: GALVES, C.; ORLANDI, E.; OTTONI, P. (Orgs.). O texto: leitura e escrita. Campinas: Pontes Editores, 1988.

VOLOCHINOV, V. N./BAKHTIN, M. Marxismo e filosofia da linguagem. São Paulo: Hucitec, 1979.

VÓVIO, C. L. Entre discursos: representações, práticas e identidades leitoras de alfabetizadores de pessoas jovens e adultas. Tese (Doutorado em Lingüística Aplicada) - Instituto de Estudos da Linguagem, Universidade Estadual de Campinas, 2007.

Recebido em 16/08/08. Aprovado em 23/09/08.

Title: New literacy studies and language teacher education

Author: Angela B. Kleiman

Abstract: The aim of this paper is to present some contributions from the research perspective known as New Literacy Studies - the study of reading and writing practices in social life - for teacher education programs. We discuss first the ethical aspects of that approach, related to the qualitative methods used, that protect the researcher from the ever present danger of reproducing teacher stereotypes. Next, we analyze the specific knowledge demands being made to literacy teachers in official documents, and finally, based upon our critical analysis of those demands, we explore an alternative teacher education strategy centered arround the participation in social practices.

Keywords: literacy; literacy teacher education programs; mother tongue; social practice

Titre: Les études dans la littératie et dans la formation du professeur de langue maternelle

Auteur: Angela B. Kleiman

Résumé: Ce travail a comme objectif discuter quelques contributions des Études de la Littératie - l'étude des pratiques qui ont un rapport avec l'écriture dans toute activité de la vie sociale - pour la réflexion sur la formation du professeur de langue maternelle. Tout d'abord, on discutera quelques aspects éthiques de cette approche, qui ont un rapport à la méthode qualitative de recherche, qui défendent le chercheur du danger, toujours constant, d'avoir ses résultats de la recherche employés dans la reproduction de critiques et stéréotypes à propos de l'enseignant. Ensuite, on analysera, des documents qui prescrivent, évaluent ou informent les actions du professeur, les

KLEIMAN - Os estudos de letramento e a formação... 
exigences par rapport aux savoirs spécifiques de ceux qui alphabétisent et professeurs de langue maternelle. Enfin, ayant comme base l'analyse critique des ces exigences, on exploitera una alternative de formation basée dans la participation dans la pratique sociale.

Mots-clés: littératie; formation du professeur; langue maternelle; pratique sociale.

Título: Los estudios de literacia y la formación del profesor de lengua materna

Autor: Angela B. Kleiman

Resumen: Este trabajo tiene por objetivo discutir algunas contribuciones de los Estudios de la Literacia - el estudio de las prácticas relacionadas con la escrita en toda actividad de la vida social — para la reflexión sobre la formación del profesor de lengua materna. Primeramente, discutiremos aspectos éticos de ese abordaje, relacionados al método cualitativo de la pesquisa, que resguardan al investigador del peligro, siempre constante, de sus resultados de investigación ser utilizados para la reproducción de críticas y estereotipos sobre el docente. Enseguida, analizaremos, en documentos que prescriben, evalúan o informan las acciones del profesor, las exigencias en relación a los saberes específicos de los alfabetizadores y profesores de lengua materna. Finalmente, con base en el análisis crítico de esas exigencias, exploraremos una alternativa de formación basada en la participación en la práctica social.

Palabras-clave: literacia; formación del profesor; lengua materna; práctica social. 